\title{
Sulforaphane and myricetin act synergistically to induce apoptosis in 3T3-L1 adipocytes
}

\author{
ANJUN YAO $^{1 *}$, YINGZHUO SHEN $^{1,2^{*}}$, ZHUANGWEI ZHANG $^{1 *}$, ZUQUAN ZOU $^{1 *}$, \\ ANSHI WANG ${ }^{1}$, SHIYONG CHEN ${ }^{1}$, HUIQIN ZHANG ${ }^{1}$, FEN CHEN $^{3}$, JINSHUN ZHAO $^{1}$, \\ ZHONGMING $\mathrm{CHEN}^{4}$, YUJUAN SHAN ${ }^{5}$ and XIAOHONG ZHANG ${ }^{1}$ \\ ${ }^{1}$ Institute of Preventative Medicine, School of Medicine, Ningbo University, Ningbo, Zhejiang 315211; \\ ${ }^{2}$ YinZhou District Center of Disease Control, Ningbo, Zhejiang 315010; ${ }^{3}$ The Affiliated Hospital of School of Medicine of \\ Ningbo University, Ningbo; ${ }^{4}$ Ningbo Kangning Hospital, Ningbo, Zhejiang 315210; \\ ${ }^{5}$ School of Food Science and Engineering, Harbin Institute of Technology, Harbin, Heilongjiang 150090, P.R. China
}

Received April 2, 2016; Accepted March 9, 2017

DOI: $10.3892 / \mathrm{mmr} .2017 .8235$

\begin{abstract}
The aim of the present study was to investigate whether sulforaphane (SFN) and myricetin (Myr) synergistically induce apoptosis in adipocytes. The viability of mature 3T3-L1 adipocytes treated with $40 \mu \mathrm{M} \mathrm{SFN}$ and/or $100 \mu \mathrm{M}$ Myr was assessed using an MTT assay. Apoptosis was assessed by Hoechst 33258 nuclear staining, and by detection of single-stranded DNA using an enzyme-linked immunosorbent assay. Compared with the effects of each compound alone, the combination of SFN and Myr synergistically reduced cell viability, induced apoptosis, increased pro-apoptotic Bcl-2 associated $\mathrm{X}$ protein expression, decreased anti-apoptotic B-cell lymphoma-2 expression, enhanced Bcl-2-associated death promoter $(\mathrm{Bad})$ translocation from the cytoplasm to the mitochondria, and reduced Bad phosphorylation at Ser112. These effects were accompanied by increased cleavage of caspase 3 and poly-ADP-ribose-polymerase. In addition, combined SFN and Myr treatment significantly decreased the protein expression levels of phosphorylated AKT serine/threonine kinase 1 (Akt) at Ser473, as well as the phosphorylation of the downstream protein ribosomal protein, S6 kinase $\beta-1$. Therefore, SFN plus Myr was a more potent inducer of apoptosis in 3T3-L1 adipocytes than either compound alone. The results of the present study suggest
\end{abstract}

Correspondence to: Professor Xiaohong Zhang, Institute of Preventative Medicine, School of Medicine, Ningbo University, 818 Fenghua road, Jiangbei, Ningbo, Zhejiang 315211, P.R. China

E-mail: zhangxiaohong1@nbu.edu.cn

Professor Yujuan Shan, School of Food Science and Engineering, Harbin Institute of Technology, 92 West Great Street, Nangang, Harbin, Heilongjiang 150090, P.R. China

E-mail: yujuan_72@163.com

${ }^{*}$ Contributed equally

Key words: sulforaphane, myricetin, apoptosis, 3T3-L1 adipocytes that the mechanism of SNF/Myr-induced apoptosis involved activation of the Akt-mediated mitochondrial apoptotic pathway. This may aid treatment of animal models of obesity and preclinical testing.

\section{Introduction}

Obesity is a global public health problem due to its close positive association with several severe chronic diseases, including type 2 diabetes, cardiovascular disease, and several types of cancer (1). Obesity involves abnormal or excessive fat accumulation in adipose tissue, and occurs as a result of adipocyte hyperplasia and hypertrophy (2). Although the mass of adipose tissue generally depends on the balance between adipogenesis and lipolysis, adipocyte apoptosis is an additional important contributor to the reduction of body fat $(3,4)$. The reduction in the number of adipocytes via induction of adipocyte apoptosis is therefore a potential strategy to attenuate obesity.

Sulforaphane (SFN), an isothiocyanate enriched in cruciferous vegetables, such as broccoli and broccoli sprouts, possesses a wide range of properties, including antioxidant (5), anticholesterol (6) and anticancer effects (7). SFN exerts an anticancer effect by inducing tumor cell apoptosis $(8,9)$. A previous study demonstrated that SFN treatment reduced the body weight of obese mice (10). In addition, SFN was observed to inhibit adipogenesis and stimulate lipolysis in pre-adipocytes and adipocytes in vitro $(11,12)$. In a previous study, treatment of mature 3T3-L1 adipocytes with $60 \mu \mathrm{M}$ SFN induced apoptosis by inhibiting the AKT serine/threonine kinase 1 (Akt) signaling pathway (13). Therefore, SFN may be a promising agent for the treatment or prevention of obesity via the induction of adipocyte apoptosis.

Myricetin (Myr; 3,5,7-trihydroxy-2-(3,4,5-trihydroxyphe nyl)-4-chromenone) is a major dietary flavonoid, commonly present in tea, berries and medicinal herbs. It has been demonstrated to possess antioxidant, anti-inflammatory, and anticancer properties (14-17). Myr functions as a potent anti-apoptotic inhibitor in cancer cell lines by regulating phosphatidylinositol 3 kinase (PI3K) and extracellular mitogen-activated protein kinase (18). These pathways affect 
cancer-cell growth and survival $(19,20)$. Previous studies have demonstrated that Myr exhibits anti-obesity activities in vivo and in vitro $(21,22)$. In 3T3-L1 adipocytes, treatment with $100 \mu \mathrm{M}$ Myr induced a significant decrease in intracellular triglyceride accumulation, inhibited pre-adipocyte differentiation, and enhanced mature-adipocyte lipolysis; however, it did not reduce cell viability (22). There is a growing body of evidence from studies investigating drug discovery from natural products, which are increasing in popularity. Administration of a combination of natural compounds has become increasingly attractive for the treatment of obesity, as there is some evidence to suggest that multi-drug combinations lead to pharmacological potentiation, which optimistically leads to lower doses, fewer adverse side effects, and an extended treatment window (23-26). Although SFN and Myr are well tolerated, it is not yet clear whether Myr induces apoptosis in adipocytes, or whether the combination of Myr and SFN may exert a stronger effect than either compound alone. Therefore, the effect of combined treatment of $40 \mu \mathrm{M} \mathrm{SFN} \mathrm{(S40)} \mathrm{and} 100 \mu \mathrm{M}$ Myr (M100) on 3T3-L1 adipocyte apoptosis was investigated in the present study. The results demonstrated that combined treatment with SFN and Myr significantly increased the level of adipocyte apoptosis induction, when compared with either agent alone. In addition, this enhanced effect on the level of apoptosis was associated with activation of the mitochondrial apoptotic pathway mediated by Akt. Therefore, SFN plus Myr treatment may be advantageous for induction of adipocyte apoptosis, as the two compounds appear to target the same pharmacological pathway.

\section{Materials and methods}

Cell culture and reagents. The mouse 3T3-L1 pre-adipocyte cell line was obtained from the American Type Culture Collection (Manassas, VA, USA) and was maintained at $37^{\circ} \mathrm{C}$ and $5 \% \mathrm{CO}_{2}$ in Dulbecco's modified Eagle's medium (DMEM; GE Healthcare Life Sciences, Chalfont, UK) supplemented with $10 \%$ calf serum (CS) or $10 \%$ fetal bovine serum (FBS; Zhejiang Tianhang Biotechnology Co., Ltd., Huzhou, China), as indicated for each procedure, plus $100 \mathrm{U} / \mathrm{ml}$ penicillin, and $100 \mathrm{mg} / \mathrm{ml}$ streptomycin (Sigma-Aldrich; Merck KGaA, Darmstadt, Germany). Myr, SFN, insulin (INS), 3-isobutyl-1-methylxanthine (IBMX), dexamethasone (DEX), and Oil Red O dye were purchased from Merck KGaA. Primary antibodies against Akt (catalog no. 9272), phosphorylated

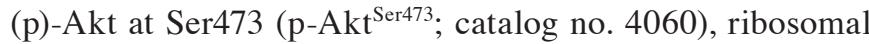
protein S6 kinase $\beta-1$ (alternatively known as p70S6K1; catalog no. 2708), p-p70S6K1 (catalog no. 9208), caspase 3 (catalog no. 9662), poly-ADP-ribose-polymerase (PARP; catalog no. 9532), the B-cell lymphoma-2 (Bcl-2; catalog no. 3498) apoptosis regulator, $\mathrm{Bcl}-2$-associated death promoter (Bad; catalog no. 9292), and p-Bad at Ser112 (p-Bad ${ }^{\text {ser112; }}$ catalog no. 9291) were purchased from Cell Signaling Technology, Inc. (Danvers, MA, USA). Primary antibodies against Bcl-2 associated X (Bax) apoptosis regulator (catalog no. AB026) was purchased from Beyotime Institute of Biotechnology (Haimen, China). The primary antibody against $\beta$-actin was purchased from Santa Cruz Biotechnology, Inc., Dallas, TX, USA (catalog no. sc-130656). The horseradish peroxidase-conjugated secondary antibodies (catalog no. BM 2006 and BA1025) were purchased from Wuhan Boster Biological Technology, Ltd. (Wuhan, China).

Adipocyte differentiation. 3T3-L1 pre-adipocytes cultured until $\sim 90 \%$ confluent $\left(\mathrm{D}_{0}\right)$ following 2 days of incubation with $10 \% \mathrm{CS} / \mathrm{DMEM}$ growth medium. The medium was then replaced with $10 \%$ FBS/DMEM supplemented with $10 \mu \mathrm{g} / \mathrm{ml}$ INS, $1 \mu \mathrm{M}$ DEX and $0.5 \mathrm{mM}$ IBMX to induce differentiation. Following 2 days $\left(\mathrm{D}_{2}\right)$, the medium was replaced with $10 \%$ FBS/DMEM containing $10 \mu \mathrm{g} / \mathrm{ml}$ INS for a further 2 days $\left(D_{4}\right)$. This was followed by culture in the $10 \%$ CS/DMEM growth medium for an additional 6 days; during which time the medium was refreshed every other day. At 10 days following induction of differentiation $\left(D_{10}\right),>90 \%$ of the cells consisted of mature adipocytes, which contained an abundance of lipid droplets and were ready for treatment.

Oil red $O$ staining. At the end of differentiation $\left(\mathrm{D}_{10}\right)$, the mature adipocytes were washed with phosphate-buffered saline (PBS) and fixed with $10 \%$ neutral buffered formalin for $30 \mathrm{~min}$ at room temperature. The cells were then washed with PBS and subsequently stained with filtered $0.5 \%(\mathrm{w} / \mathrm{v})$ Oil red $\mathrm{O}$ solution for $30 \mathrm{~min}$ at room temperature in the dark. Cells were then washed three times with distilled water. Photographs of the Oil Red O-stained cells were captured using a Nikon digital camera system (Nikon Corporation, Tokyo, Japan). A total of $99 \%(\mathrm{v} / \mathrm{v})$ isopropanol was then added to the cells and incubated for $5 \mathrm{~min}$ at room temperature to remove the dye, and the lipid content of the cells was quantified by spectrophotometry at $570 \mathrm{~nm}$.

MTT assay. The viability of mature adipocytes was determined using an MTT assay kit (Beyotime Institute of Biotechnology, Haimen, China), which measures the production of formazan by catalytically active cells and therefore provides a measure of the number of viable cells. Pre-adipocytes were seeded onto a 96-well plate at a density of $2.5 \times 10^{3}$ cells/well and induced to differentiate into mature adipocytes using the aforementioned methods. At $\mathrm{D}_{10}$ the mature adipocytes were treated with S40 and/or M100 for $24 \mathrm{~h}$. Following treatment, the cells were incubated with $0.5 \mathrm{mg} / \mathrm{ml} \mathrm{MTT} \mathrm{reagent} \mathrm{for} 3 \mathrm{~h}$ at $37^{\circ} \mathrm{C}$ to allow the formation of formazan crystals. Dimethyl sulfoxide $(150 \mu \mathrm{l})$ was subsequently added to each well to dissolve the formazan crystals. The optical density (OD) was determined by measuring the absorbance of wells at $570 \mathrm{~nm}$ using a microplate reader. Inhibition of cell viability was calculated as follows: Inhibition $(\%)=\left[1-\left(\mathrm{OD}_{\text {treated adipocytes }} / \mathrm{OD}_{\text {untreated }}\right.\right.$ adipocytes)] x100.

Measurement of adipocyte apoptosis. Pre-adipocytes were seeded in $6-\mathrm{cm}$ culture dishes $\left(4 \times 10^{4}\right.$ cells/dish) coated with poly-lysine, and induced to differentiate into mature adipocytes using the aforementioned methods. Mature adipocytes were then treated with S40 and/or M100 for $24 \mathrm{~h}$. The cells were subsequently fixed with $4 \%$ paraformaldehyde at room temperature for $10 \mathrm{~min}$, washed twice with PBS and stained with $10 \mu \mathrm{g} / \mathrm{ml}$ Hoechst 33258 solution for $5 \mathrm{~min}$ in the dark. Cells were washed with cold PBS and a drop of anti-fade mounting medium (Beyotime Institute of Biotechnology) was added. Alterations in nuclear morphology were observed under 
an inverted fluorescence microscope (Olympus IX51 Inverted Microscope; Olympus Corporation, Tokyo, Japan).

The ApoStrand ${ }^{\mathrm{TM}}$ ELISA Apoptosis Detection kit (Enzo Life Sciences, Inc., Farmingdale, NY, USA) was used to quantify the levels of single-stranded DNA (ssDNA) generated during apoptosis, according to the manufacturer's instructions. Briefly, mature 3T3-L1 adipocytes $\left(2.5 \times 10^{3}\right.$ cells/well) were transferred to 96-well plates following treatment with S40 and/or M100 for $24 \mathrm{~h}$. The cells were fixed at room temperature for 30 min with $4 \%$ formamide, and then the ssDNA in apoptotic cells was stained with a mixture of the primary antibody and the peroxidase-labeled secondary antibody provided with the kit. The cells were subsequently incubated with peroxidase substrate at room temperature for $45 \mathrm{~min}$, and the absorbance at $405 \mathrm{~nm}$ was read.

Western blotting. Following treatment with $\mathrm{S} 40$ and/or M100 for $24 \mathrm{~h}, \sim 4 \times 10^{7}$ mature adipocytes were harvested for extraction of mitochondrial and cytoplasmic protein, and $\sim 1 \times 10^{7}$ cells were used to extract total protein. Briefly, $2 \mathrm{ml}$ mitochondrial separation reagent containing $1 \mathrm{mM}$ PMSF (Beyotime Institute of Biotechnology) was added, and then shaken at $4^{\circ} \mathrm{C}$ for $3 \mathrm{~min}$ followed by centrifugation at $600 \mathrm{x} \mathrm{g}$ for $10 \mathrm{~min}$ at $4^{\circ} \mathrm{C}$ for $10 \mathrm{~min}$. The supernatant (cytoplasm) and the precipitation (mitochondria) were separated and lysed in Nonidet P-40 lysis buffer on ice for $1 \mathrm{~h}$. The supernatant was collected by centrifugation at $12,000 \mathrm{x}$ g for $15 \mathrm{~min}$ at $4^{\circ} \mathrm{C}$. The protein concentration was quantified using an enhanced bicinchoninic acid protein assay kit (Beyotime Institute of Biotechnology). Protein samples (50 $\mu \mathrm{g} / \mathrm{lane})$ were electrophoresed by $10 \%$ SDS-PAGE and transferred to a polyvinylidene fluoride membrane. The membranes were blocked in blocking buffer containing 5\% nonfat dry milk in Tris-buffered saline with $0.05 \%$ Tween 20 (TBST) for $1 \mathrm{~h}$ at room temperature. The membranes were then probed with the specific primary antibodies (diluted 1:1,000) overnight at $4^{\circ} \mathrm{C}$ in TBST. The membranes were subsequently washed with TBST three times for 5 min each time, and incubated with the horseradish peroxidase-conjugated secondary antibodies (diluted 1:10,000) for $1.5 \mathrm{~h}$ at room temperature. Membranes were washed again with TBST, developed with an enhanced chemiluminescence kit (Roche Applied Science, Penzberg, Germany) and exposed to X-ray film in a dark room. The protein bands were analyzed using a Gel Doc ${ }^{\text {TM }} \mathrm{XR}^{+}$imaging system (Bio-Rad Laboratories, Inc., Hercules, CA, USA).

Statistical analysis. Data are expressed as the mean \pm standard deviation of at least three independent experiments. SPSS version 10.0 (SPSS, Inc., Chicago, IL, USA) was used for statistical analysis. One-way analysis of variance and the Student-Newman-Keuls post hoc test were used to evaluate statistical differences among groups. $\mathrm{P}<0.05$ was considered to indicate a statistically significant difference.

\section{Results}

Mature adipocyte determination. At $\mathrm{D}_{10}$ of adipocyte differentiation, the vast majority of 3T3-L1 cells appeared to contain Oil Red O-stained lipid droplets, which indicated that adipocyte maturation had occurred (Fig. 1).
SFN and Myr combined decreased adipocyte viability. The results of the MTT assay revealed that treatment with S40 or M100 reduced the viability of mature adipocytes by $14.74 \pm 0.02$ and $9.36 \pm 0.03 \%$, respectively, when compared with untreated cells ( $\mathrm{P}<0.05$; Fig. 2A, Table I). However, when S40 and M100 were applied in combination, cell viability was reduced by $33.07 \pm 0.02 \%$ when compared with the untreated cells $(\mathrm{P}<0.05$; Table I). Treatment with these agents together did not demonstrate an additive effect, as this would have led to a decrease in cell viability of $24.10 \pm 0.05 \%$ ( $\mathrm{P}<0.05$; Table I), which suggests that the observed effect was synergistic.

Oil Red O staining revealed that treatment with SFN and/or Myr decreased the number of lipid droplets that accumulated in mature adipocytes (Fig. 2B). Quantitative spectrophotometry analysis revealed that S40 and/or M100 treatment significantly reduced the lipid content of the cells when compared with untreated cells $(\mathrm{P}<0.05$; Fig. $2 \mathrm{C}$, Table I). Combined treatment with S40 and M100 was not associated with a significant reduction in cellular lipid content when compared with S40 or M100 treatment alone (Table I).

Combined SFN and Myr treatment induced apoptosis. Hoechst 33258 nuclear staining of mature adipocytes revealed that cells displayed characteristic features of apoptosis, including shrinkage, nuclear fragmentation, and chromatin condensation following treatment with SFN and/or Myr for $24 \mathrm{~h}$ (Fig. 3A). Apoptosis was further assessed by quantifying the level of ssDNA in cells, which may be used as a marker of apoptotic cells. The ssDNA levels indicated that, while SFN and Myr treatment alone induced apoptosis in adipocytes when compared with the untreated control cells, the effect of combined treatment was significantly greater than that of each compound alone ( $\mathrm{P}<0.05$; Fig. 3B). Compared with the control, S40 and M100 increased the levels of apoptosis by $27.38 \pm 0.08$ and $9.74 \pm 0.08 \%$, respectively $(\mathrm{P}<0.05$; Table I). However, combined treatment with S40 and M100 increased apoptosis by $108.04 \pm 0.18 \%$ when compared with the control $(\mathrm{P}<0.05$; Table I). The calculated additive effect would have led to an increase in apoptosis levels of $37.11 \pm 0.16 \%$ when compared with the controls $(\mathrm{P}<0.05$; Table I), which therefore suggests that SFN and Myr act synergistically to induce apoptosis in adipocytes.

Involvement of the mitochondrial apoptotic pathway. Bcl-2 family proteins are critical regulators of the mitochondrial apoptotic pathway. The ratio of Bax to Bcl-2 is important in determining cell fate (25). In the present study, SFN treatment markedly increased Bax protein expression levels, while Myr demonstrated no observable effect when compared with the control (Fig. 4A). Neither SFN nor Myr treatment demonstrated any observable effect on Bcl-2 expression levels at the concentrations tested (Fig. 4A). However, treatment with SFN and Myr combined increased Bax expression and decreased Bcl-2 expression levels when compared with the control, thus altering the Bax/Bcl-2 ratio in favor of apoptosis (Fig. 4A). In addition, combined treatment markedly increased Bad expression in the mitochondria when compared with the control, which suggests that Bad translocation from the cytoplasm to the mitochondria was activated, thus promoting apoptosis (Fig. 4B). Furthermore, phosphorylation of Bad at Ser112, 
Table I. Percentage change in viability, apoptosis and cellular lipid of 3T3-L1 mature adipocytes treated with $40 \mu \mathrm{M}$ SFN (S40) plus $100 \mu \mathrm{M}$ Myr (M100).

Treatment (\% change)

\begin{tabular}{|c|c|c|c|}
\hline & \\
\hline & Inhibition of cell viability ${ }^{\mathrm{a}}$ & Increase of $\mathrm{ssDNA}^{\mathrm{b}}$ & Decrease of intracellular lipid ${ }^{c}$ \\
\hline Control & $0.00 \pm 0.03^{\mathrm{u}}$ & $0.00 \pm 0.05^{\mathrm{u}}$ & $0.00 \pm 1.61^{\mathrm{u}}$ \\
\hline S40 & $14.74 \pm 0.02^{\mathrm{uv}}$ & $27.38 \pm 0.08^{\mathrm{uv}}$ & $13.58 \pm 1.26^{\mathrm{uv}}$ \\
\hline M100 & $9.36 \pm 0.03^{\mathrm{uvw}}$ & $9.74 \pm 0.08^{\mathrm{uvw}}$ & $9.44 \pm 0.68^{\mathrm{uvw}}$ \\
\hline $\mathrm{S} 40+\mathrm{M} 100$ & $33.07 \pm 0.02^{x}$ & $108.04 \pm 0.18^{x}$ & $14.83 \pm 0.73^{\mathrm{uv}}$ \\
\hline Calculated additive response ${ }^{\mathrm{d}}$ & $24.10 \pm 0.05^{\mathrm{xy}}$ & $37.12 \pm 0.16^{\mathrm{xy}}$ & $23.02 \pm 1.94^{\mathrm{x}}$ \\
\hline
\end{tabular}

Values are calculated according to the equation below: anhibition of cell viability $\%=[1-($ viability of treated group/viability of control group)] $\mathrm{x} 100 \%$. ${ }^{\mathrm{b}}$ Increase of ssDNA $\%=[(\mathrm{ssDNA}$ of treated group/ssDNA of control group $)-1] \mathrm{x} 100 \%$. ${ }^{\mathrm{C}}$ Decrease of cellular lipid $\%=[1-(\mathrm{OD}$ treated group/OD control)]x100\%. ${ }^{\mathrm{d} C a l c u l a t e d}$ additive response is the sum of the individual SFN and Myr treatments. ${ }^{\mathrm{uvwx}}$ means not denoted with a common letter are significantly different, $\mathrm{P}<0.05$.

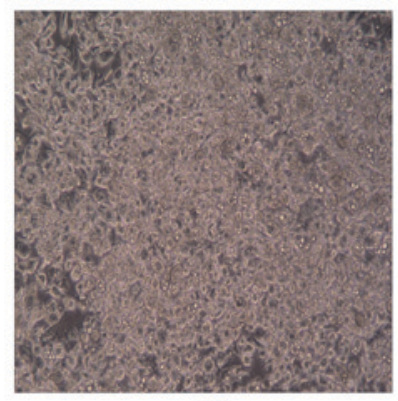

(a)

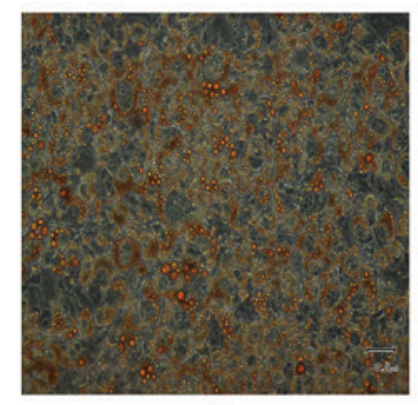

(b)

Figure 1. Morphology of mature 3T3-L1 adipocytes. (A) Images of mature adipocytes obtained by phase-contrast microscopy following 10 days induction of differentiation (magnification, x200). (B) Mature adipocytes stained with Oil red $\mathrm{O}$ following 10 days induction of differentiation (magnification, x200).

which is thought to be necessary and sufficient to promote cell survival, was markedly decreased in the cells treated with SFN plus Myr compared with control cells or cells treated with each compound alone (Fig. 4B). Caspase 3 is the main executor caspase of the majority of programmed cell-death processes (27). As demonstrated in Fig. 4A, treatment with either SFN or Myr for $24 \mathrm{~h}$ led to an increase in the levels of cleaved caspase 3 and increased cleavage of the downstream DNA-repair enzyme, PARP, from its native $116 \mathrm{kDa}$ form to the inactive $89 \mathrm{kDa}$ form. As expected, combined treatment additionally induced caspase 3 cleavage and PARP inactivation (Fig. 4A).

Myr potentiated the effect of SFN on Akt phosphorylation. Western blot analysis revealed that SFN or Myr treatment alone did not demonstrate any observable effect on Akt phosphorylation at Ser473; however, combined treatment with these agents markedly inhibited Akt phosphorylation when compared with the controls (Fig. 4C). Total Akt expression levels were unaffected in cells treated with SFN and/or Myr (Fig. 4C). As expected, combined SFN and Myr treatment was associated with an observable decrease in the levels of p-p70S6K1 when compared with controls (Fig. 4C). SFN treatment alone decreased p70S6K1 phosphorylation; however, this effect was not as pronounced as combined SFN and Myr treatment (Fig. 4C). The expression levels of total p70S6K1 in adipocytes were not altered in response to SFN and/or Myr treatment (Fig. 4C).

\section{Discussion}

A number of natural compounds have been reported to induce apoptosis in 3T3-L1 pre-adipocytes or adipocytes, indicating that they may be promising agents for the treatment of obesity (28). It has become evident that the combined use of several natural products may be more effective in the prevention and treatment of obesity than conventional, single-agent regimens, due to synergistic effects and fewer adverse side effects (29). In the present study, combined treatment of 3T3-L1 adipocytes with SFN and Myr decreased cell viability to a greater extent than the additive effect of each compound alone. In addition, the SFN plus Myr treatment induced significantly higher levels of apoptosis in adipocytes when compared with each compound alone. This was determined by measuring the characteristic phenotypic alterations associated with apoptosis, including nuclear fragmentation, chromatin condensation, and ssDNA levels.

The Bcl-2 family proteins, including the anti-apoptotic proteins Bax, Bcl-2 antagonist/killer 1 and Bad, as well as pro-apoptotic proteins, Bcl-2, Bcl-2-like 1, and Bcl-2 like 2 , are important components in the regulation of apoptosis. $\mathrm{Bcl}-2$ is located on the surface of mitochondria where it maintains the integrity of the mitochondrial membrane and functions as a negative regulator of apoptosis (30). By contrast, Bax usually resides in the cytosol. Its translocation to the mitochondria leads to the activation of an apoptotic cascade in response to apoptotic stimuli (31). Therefore, the relative $\mathrm{Bax} / \mathrm{Bcl}-2$ ratio is an important determinant of whether cells will undergo apoptosis. Increased Bax and downregulated Bcl-2 expression has been reported in capsaicin-induced apoptosis of 3T3-L1 adipocytes (32). In addition, curcumin-induced apoptosis in SW872 human adipocytes is accompanied by an increase in the Bax/Bcl-2 


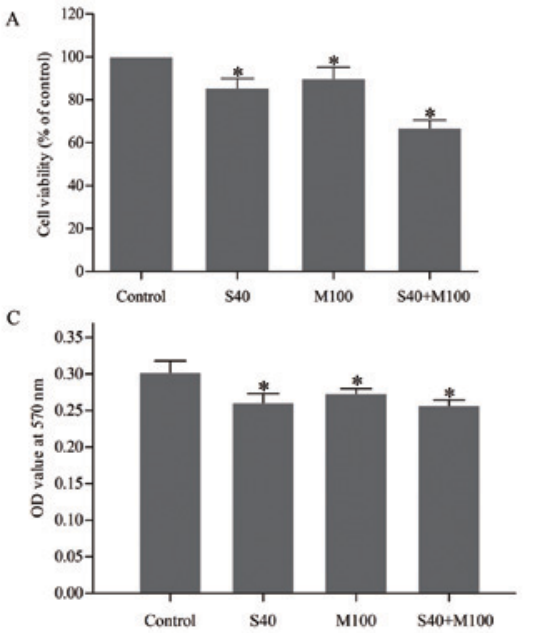

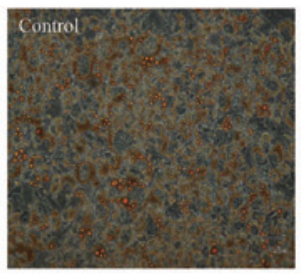
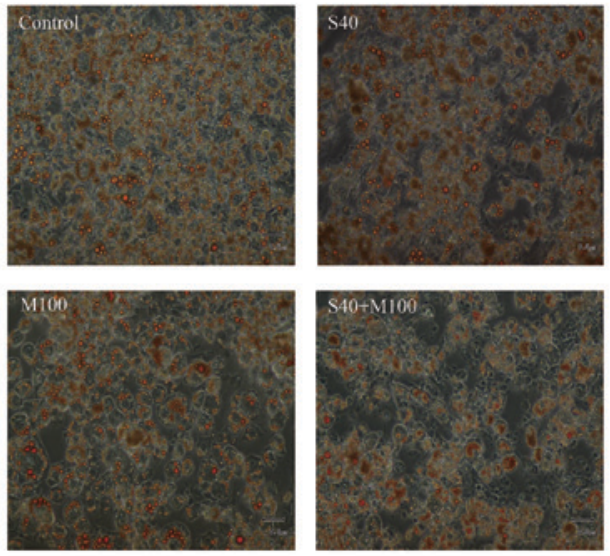

Figure 2. Effects of $24 \mathrm{~h} \mathrm{SFN}$ and/or Myr treatment on the viability and lipid content of mature 3T3-L1 adipocytes. (A) The viability of mature adipocytes treated with SFN and/or Myr for $24 \mathrm{~h}$, as determined using the MTT assay. (B) The morphology of mature adipocytes treated with SFN and/or Myr for $24 \mathrm{~h}$. Images of mature adipocytes obtained by phase-contrast microscopy (magnification, x200). (C) Cellular lipid content was determined by measuring the absorbance at $570 \mathrm{~nm}$. Data are expressed as the mean \pm standard deviation of three independent experiments. ${ }^{*} \mathrm{P}<0.05$ vs. untreated control cells. SFN, sulforaphane; Myr, myricetin; S40, $40 \mu \mathrm{M}$ SFN treatment; M100, $100 \mu \mathrm{M}$ Myr treatment.
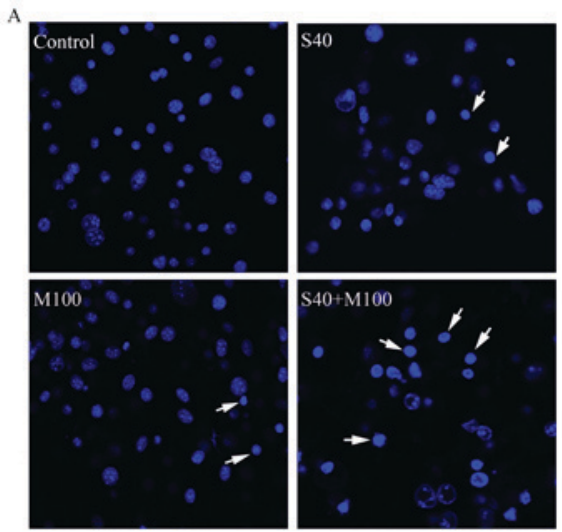

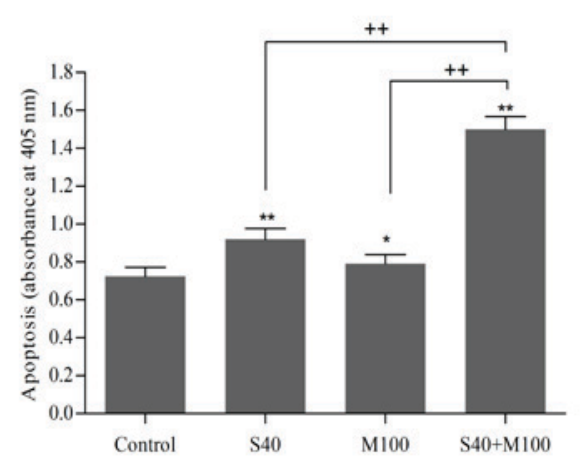

Figure 3. Apoptosis levels in mature 3T3-L1 adipocytes following treatment with SFN and/or Myr. (A) Analysis of the characteristic alterations of nuclear morphology associated with apoptosis, as determined by Hoechst 33258 staining of cells treated with SFN and/or Myr for 24 h. White arrows demonstrated apoptosis. Magnification, x200. (B) The level of apoptosis in mature adipocytes treated with SFN and/or Myr, as determined using a single-stranded DNA enzyme-linked immunosorbent assay. Data are expressed as the mean \pm standard deviation of three independent experiments. ${ }^{*} \mathrm{P}<0.05$ and ${ }^{* *} \mathrm{P}<0.01$ vs. untreated control cells; ${ }^{++} \mathrm{P}<0.01$ as indicated. SFN, sulforaphane; Myr, myricetin; S40, $40 \mu \mathrm{M}$ SFN treatment; M100, $100 \mu \mathrm{M}$ Myr treatment.

ratio (33). In the present study, combined treatment with SFN and Myr significantly increased the Bax/Bcl-2 ratio in adipocytes when compared with either agent alone. A previous study demonstrated that, at doses of $\geq 60 \mu \mathrm{M}$, Bad was involved in the pro-apoptotic effects of SFN (13). In the present study, combined treatment of adipocytes with $40 \mu \mathrm{M}$ SFN and $100 \mu \mathrm{M}$ Myr induced the translocation of Bad to the mitochondria and the de-phosphorylation of Bad at Ser112.

Caspase 3 is a crucial mediator of apoptosis and is indispensable for apoptosis in numerous cell types (27). Activated caspase 3 cleaves the downstream cell death-associated substrate, PARP, into 89 and $28 \mathrm{kD}$ fragments. The cleaved PARP fragments are hallmarks of the progress of apoptosis (34). A number of previous studies have reported that several natural products activate caspase 3 and induce apoptosis in 3T3-L1 adipocytes $(28,33)$. The present study demonstrated that the treatment of adipocytes with SFN and Myr combined, induced caspase 3 activation and PARP cleavage. These results support the hypothesis that the enhanced effects of combined SFN and Myr treatment on adipocyte apoptosis are associated with activation of the mitochondrial apoptosis pathway.

The Akt signaling pathway serves an important role in the regulation of cell death and cell survival (19). SFN has been reported to induce programmed death in Caco-2 colorectal cancer cells via activation of PI3K/Akt (35). A previous study demonstrated that the Akt/p70S6K1/Bad signaling pathway may be involved in Myr-induced apoptosis in HepG2 hepatocellular carcinoma cells (36). In the present study, treatment of adipocytes with SFN and Myr combined significantly inhibited the phosphorylation of Akt and its downstream target, p70S6K1, which suggests that the Akt signaling pathway may 

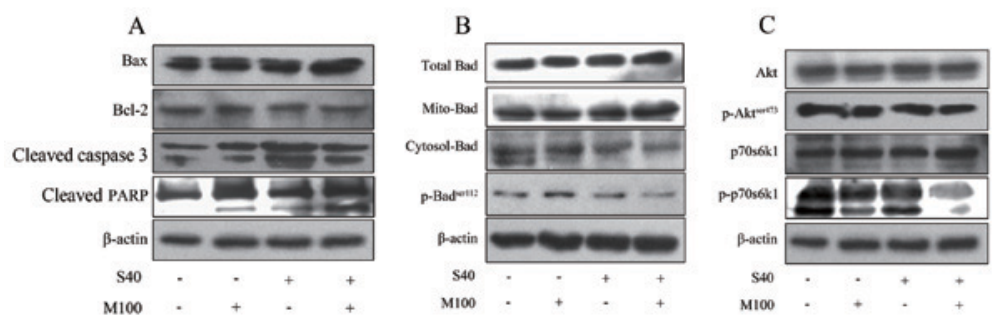

$\mathrm{D}$
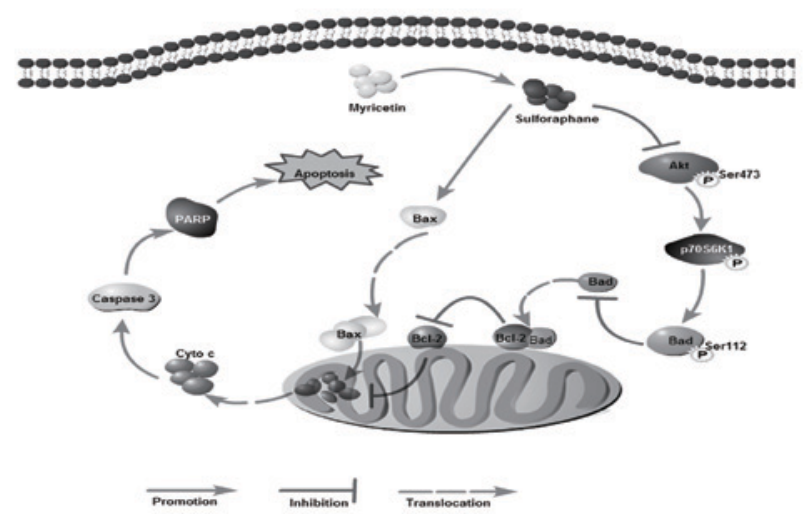

Figure 4. Expression of apoptosis-associated proteins in 3T3-L1 adipocytes treated with SFN and/or Myr for $24 \mathrm{~h}$, as determined by western blot analysis. Images of blots showing the protein expression levels of (A) Bax, Bcl-2, cleaved caspase 3, and cleaved PARP. (B) Total, cytoplasmic and mitochondrial $\mathrm{Bad}$, and $\mathrm{p}-\mathrm{Bad}^{\mathrm{Ser} 112}$. (C) Akt, p-Akt ${ }^{\mathrm{Ser} 473}, \mathrm{p} 70 \mathrm{~S} 6 \mathrm{~K} 1$, and $\mathrm{p}-\mathrm{p} 70 \mathrm{~S} 6 \mathrm{~K} 1 . \beta$-actin was used as a loading control. Representative blots of three independent experiments are shown. (D) Proposed schematic diagram of a combination of Myr and SFN-induced apoptosis of adipocyte. Myr enhanced the inhibitory effect of SFN on the Akt signaling pathway, increased SFN-induced upregulation of the Bax/Bcl-2 ratio and activation of caspase-3. SFN, sulforaphane; Myr, myricetin; Bax, Bcl-2 associated X; Bcl-2, B-cell lymphoma-2; PARP, poly-ADP-ribose-polymerase; Bad, Bcl-2-associated death promoter; p-, phosphorylated; Akt, AKT serine/threonine kinase 1; p70S6K1, ribosomal protein S6 kinase $\beta$-1; S40, $40 \mu \mathrm{M}$ SFN treatment; M100, $100 \mu \mathrm{M}$ Myr treatment.

have been involved in the observed increase in apoptosis levels induced by the combination treatment (Fig. 4D).

In conclusion, treatment with Myr and SFN combined was associated with synergistic pro-apoptotic effects in adipocytes. This increase in apoptosis may have been due to an increase in the $\mathrm{Bax} / \mathrm{Bcl}-2$ ratio, the mitochondrial translocation of Bad, the activation of caspase 3 , and inactivation of the Akt signaling pathway. The results suggest that administration of Myr and SFN combined may be beneficial for the treatment or prevention of obesity, as it provides the advantage of lowering the dose required to gain a therapeutic effect, thereby potentially minimizing side effects. Further studies investigating the effects of different Myr and SFN combination regimens in adipocytes are therefore warranted.

\section{Acknowledgements}

The present study was supported by the National Natural Science Foundation of China (grant no. 81673163 and 81450048), the Zhejiang Provincial Natural Science Foundation of China (grant no. LY14H260001), the Zhejiang Provincial Key Laboratory of Pathological and Physiological Technology (grant no. 20012E10018), Ningbo Scientific Innovation Team for Environmental Hazardous Factor Control and Prevention (2016C51001) and the School of Medicine, Ningbo Civil Outstanding Talent and Leadership Fund. The present study was partly sponsored by the K.C. Wong Magna Fund in Ningbo University and the Graduate Research Innovation Fund in Ningbo University (grant no. G16026).

\section{References}

1. World Health Organization: Fact sheet no 311. 2015. URL http:// www.who.int/mediacentre/factsheets/fs311/en/print.html. Accessed Dec. 4, 2015.

2. Jo J, Gavrilova O, Pack S, Jou W, Mullen S, Sumner AE, Cushman SW and Periwal V: Hypertrophy and/or Hyperplasia: Dynamics of adipose tissue growth. PLoS Comput Biol 5: e1000324, 2009.

3. Prins JB, Walker NI, Winterford CM and Cameron DP: Human adipocyte apoptosis occurs in malignancy. Biochem Biophys Res Commun 205: 625-630, 1994.

4. Prins JB, Walker NI, Winterford CM and Cameron DP: Apoptosis of human adipocytes in vitro. Biochem Biophys Res Commun 201: 500-507, 1994.

5. Lee YJ and Lee SH: Sulforaphane induces antioxidative and antiproliferative responses by generating reactive oxygen species in human bronchial epithelial BEAS-2B cells. J Korean Med Sci 26: 1474-1482, 2011

6. Juengel E, Maxeiner S, Rutz J, Justin S, Roos F, Khoder W, Tsaur I, Nelson K, Bechstein WO, Haferkamp A and Blaheta RA: Sulforaphane inhibits proliferation and invasive activity of everolimus-resistant kidney cancer cells in vitro. Oncotarget 7: 85208-85219, 2016.

7. Shehatou GS and Suddek GM: Sulforaphane attenuates the development of atherosclerosis and improves endothelial dysfunction in hypercholesterolemic rabbits. Exp Biol Med (Maywood) 241: 426-436, 2016.

8. Li Y, Zhang T, Korkaya H, Liu S, Lee HF, Newman B, Yu Y, Clouthier SG, Schwartz SJ, Wicha MS and Sun D: Sulforaphane, a dietary component of broccoli/broccoli sprouts, inhibits breast cancer stem cells. Clin Cancer Res 16: 2580-2590, 2010.

9. Sarkar R, Mukherjee S, Biswas J and Roy M: Sulphoraphane, a naturally occurring isothiocyanate induces apoptosis in breast cancer cells by targeting heat shock proteins. Biochem Biophys Res Commun 427: 80-85, 2012.

10. Choi KM, Lee YS, Kim W, Kim SJ, Shin KO, Yu JY, Lee MK, Lee YM, Hong JT, Yun YP and Yoo HS: Sulforaphane attenuates obesity by inhibiting adipogenesis and activating the AMPK pathway in obese mice. J Nutr Biochem 25: 201-207, 2014. 
11. Lee JH, Moon MH, Jeong JK, Park YG, Lee YJ, Seol JW and Park SY: Sulforaphane induced adipolysis via hormone sensitive lipase activation, regulated by AMPK signaling pathway. Biochem Biophys Res Commun 426: 492-497, 2012.

12. Choi KM, Lee YS, Sin DM, Lee S, Lee MK, Lee YM, Hong JT Yun YP and Yoo HS: Sulforaphane inhibits mitotic clonal expansion during adipogenesis through cell cycle arrest. Obesity (Silver Spring) 20: 1365-1371, 2012.

13. Yao A, Shen Y, Wang A, Chen S, Zhang H, Chen F, Chen Z, Wei H, Zou Z, Shan Y and Zhang X: Sulforaphane induces apoptosis in adipocytes via Akt/p70s6k1/Bad inhibition and ERK activation. Biochem Biophys Res Commun 465: 696-701, 2015.

14. Ong KC and Khoo HE: Biological effects of myricetin. Gen Pharmacol 29: 121-126, 1997.

15. Ross JA and Kasum CM: Dietary flavonoids: Bioavailability, metabolic effects, and safety. Annu Rev Nutr 22: 19-34, 2002.

16. Weng CJ and Yen GC: Flavonoids, a ubiquitous dietary phenolic subclass, exert extensive in vitro anti-invasive and in vivo anti-metastatic activities. Cancer Metastasis Rev 31: 323-351, 2012.

17. Sun F, Zheng XY, Ye J, Wu TT, Wang J and Chen W: Potential anticancer activity of myricetin in human T24 bladder cancer cells both in vitro and in vivo. Nutr Cancer 64: 599-606, 2012

18. Phillips PA, Sangwan V, Borja-Cacho D, Dudeja V, Vickers SM and Saluja AK: Myricetin induces pancreatic cancer cell death via the induction of apoptosis and inhibition of the phosphatidylinositol 3-kinase (PI3K) signaling pathway. Cancer Lett 308 : 181-188, 2011.

19. Datta SR, Brunet A and Greenberg ME: Cellular survival: A play in three Akts. Genes Dev 13: 2905-2927, 1999.

20. Bonni A, Brunet A, West AE, Datta SR, Takasu MA and Greenberg ME: Cell survival promoted by the Ras-MAPK signaling pathway by transcription-dependent and -independent mechanisms. Science 286: 1358-1362, 1999.

21. Chang CJ, Tzeng TF, Liou SS, Chang YS and Liu IM: Myricetin increases hepatic peroxisome proliferator-activated receptor $\alpha$ protein expression and decreases plasma lipids and adiposity in rats. Evid Based Complement Alternat Med 2012: 787152 , 2012.

22. Wang Q, Wang ST, Yang X, You PP and Zhang W: Myricetin suppresses differentiation of $3 \mathrm{~T} 3-\mathrm{L} 1$ preadipocytes and enhances lipolysis in adipocytes. Nut Rese 35: 317-327, 2015.

23. Yang JY, Della-Fera MA, Rayalam S and Baile CA: Enhanced effects of xanthohumol plus honokiol on apoptosis in 3T3-L1 adipocytes. Obesity (Silver Spring, Md.) 16: 1232-1238, 2008.

24. Yang JY, Della-Fera MA, Rayalam S, Ambati S, Hartzell DL, Park HJ and Baile CA: Enhanced inhibition of adipogenesis and induction of apoptosis in 3T3-L1 adipocytes with combinations of resveratrol and quercetin. Life Sci 82: 1032-1039, 2008.
25. Rayalam S, Yang JY, Della-Fera MA, Park HJ, Ambati S and Baile CA: Anti-obesity effects of xanthohumol plus guggulsterone in 3T3-L1 adipocytes. J Med Food 12: 846-853, 2009.

26. Baile CA, Yang JY, Rayalam S, Hartzell DL, Lai CY, Andersen C and Della-Fera MA: Effect of resveratrol on fat mobilization. Ann N Y Acad Sci 1215: 40-47, 2011.

27. Porter AG and Jänicke RU: Emerging roles of caspase-3 in apoptosis. Cell Death Differ 6: 99-104, 1999.

28. Rayalam S, Della-Fera MA and Baile CA: Phytochemicals and regulation of the adipocyte life cycle. J Nutr Biochem 19: 717-726, 2008.

29. Rayalam S, Della-Fera MA, Yang JY, Park HJ, Ambati S and Baile CA: Resveratrol potentiates genistein's antiadipogenic and proapoptotic effects in 3T3-L1 adipocytes. J Nutr 137 2668-2673, 2007.

30. Vander Heiden MG and Thompson $\mathrm{CB}$ : $\mathrm{Bcl}-2$ proteins: Regulators of apoptosis or of mitochondrial homeostasis? Nat Cell Biol 1: E209-E216, 1999.

31. Siddiqui WA, Ahad A and Ahsan H: The mystery of BCL2 family: Bcl-2 proteins and apoptosis: An update. Arch Toxicol 89: 289-317, 2015

32. Hsu CL and Yen GC: Effects of capsaicin on induction of apoptosis and inhibition of adipogenesis in 3T3-L1 cells. J Agric Food Chem 55: 1730-1736, 2007

33. Zhu L, Han MB, Gao Y, Wang H, Dai L, Wen Y and Na LX Curcumin triggers apoptosis via upregulation of $\mathrm{Bax} / \mathrm{Bcl}-2$ ratio and caspase activation in SW872 human adipocytes. Mol Med Rep 12: 1151-1156, 2015.

34. Agarwal A, Mahfouz RZ, Sharma RK, Sarkar O, Mangrola D and Mathur PP: Potential biological role of poly (ADP-ribose) polymerase (PARP) in male gametes. Reprod Biol Endocrinol 7: 143,2009

35. Jakubíková J, Sedlák J, Mithen R and Bao Y: Role of PI3K/Akt and MEK/ERK signaling pathways in sulforaphane- and erucin-induced phase II enzymes and MRP2 transcription, G2/M arrest and cell death in Caco-2 cells. Biochem Pharmacol 69: 1543-1552, 2005.

36. Zhang XH, Chen SY, Tang L, Shen YZ, Luo L, Xu CW, Liu Q and Li D: Myricetin induces apoptosis in HepG2 cells through Akt/p70S6K/bad signaling and mitochondrial apoptotic pathway. Anticancer Agents Med Chem 13: 1575-1581, 2013.

This work is licensed under a Creative Commons Attribution-NonCommercial-NoDerivatives 4.0 International (CC BY-NC-ND 4.0) License. 